\title{
Prediction of Landslide Position of Loose Rock Mass at Mountain Tunnel Exit
}

\author{
Ya-Qiong Wang $\mathbb{D}^{1},{ }^{1}$ Cheng-Bin $\mathrm{Ma}^{2}{ }^{2}$ and Zhi-Feng Wang ${ }^{3}{ }^{3}$ \\ ${ }^{1}$ Professor, School of Highway, Shaanxi Provincial Major Laboratory for Highway Bridge \& Tunnel, Chang'an University, \\ 710064 Xi'an, Shaanxi Province, China \\ ${ }^{2}$ Master Student, School of Highway, Shaanxi Provincial Major Laboratory for Highway Bridge \& Tunnel, Chang'an University, \\ 710064 Xi'an, Shaanxi Province, China \\ ${ }^{3}$ Associate Professor, School of Highway, Shaanxi Provincial Major Laboratory for Highway Bridge \& Tunnel, \\ Chang'an University, 710064 Xi'an, Shaanxi Province, China
}

Correspondence should be addressed to Zhi-Feng Wang; zhifeng.wang@chd.edu.cn

Received 1 February 2019; Accepted 21 April 2019; Published 14 May 2019

Academic Editor: Venu G. M. Annamdas

Copyright (c) 2019 Ya-Qiong Wang et al. This is an open access article distributed under the Creative Commons Attribution License, which permits unrestricted use, distribution, and reproduction in any medium, provided the original work is properly cited.

\begin{abstract}
Landslide of loose rock mass at mountain tunnel exit occurs easily, and prediction of landslide position is one of the engineering problems to be solved urgently. Currently, existing and used prediction methods, such as field monitoring measurement, numerical analysis, nonlinear theories, and the geometric method, play a very important role and have their limitations. For example, there is a bigger difference between calculation mode by Wang et al.'s method and actual engineering situation; besides, there exists a relatively big discrepancy between the predicted and true position. Aiming to solve this problem, this article combined theoretical analysis and actual engineering situation to establish an optimal calculation mode. At the same time, this article re-deduced instability criteria based on the stress-transferring theory and examined the factors that influence solutions. The improved method can predict landslide position more accurately because the parameters $(\beta, s, H, \alpha, \gamma, c, \varphi$, and $T)$ related to the occurrence of landslide are taken into consideration. It is pointed out that landslide possibly occurs in the case of $\Delta \geq 0$ and $Y \leq 0$. In addition, the equations $s_{1}<s<s_{2}$ and $0 \leq s \leq H / \sin \alpha$ can determine landslide position accurately. The method is applied to two engineering examples, and the calculation results show that the deviations of predictive position from the actual landslide position are only $0.10 \%$ and $0.07 \%$, respectively, indicating that prediction results are accurate and reliable. It is suggested that the proposed method is a useful tool in the design of tunnel engineering.
\end{abstract}

\section{Introduction}

Generally speaking, the run-through of a tunnel should choose a two-way excavation method. Connection point position should be in class IV and above rock mass segment [1-3]. However, the work face of mountain tunnel exit is difficult to unfold and a two-way excavation method is even invalid due to the constraints of geographical conditions, construction progress delay, and other factors in the construction [4-6]. At this point, it is often necessary to adopt the construction form of one-way driving to be out of a tunnel according to the actual engineering situation. When a mountain tunnel is excavated to the exit in a one-way driving way, landslides easily occur for the cover is thinner and the rock mass is in the junction of soil and rock with obvious lithology changes and serious efflorescence. Once landslide occurs, it may run to the plane and cause giant loss of life and property. At the same time, research shows that landslide accounts for more than $90 \%$ of the probability of all kinds of crucial geological hazards [7-10]. Also, it is the focal point of geological hazard prevention in tunnel construction [11-13]. Therefore, it is of great practical significance to expand prediction of landslide and landslide position at mountain tunnel exit.

Landslide is a form of the surrounding rock instability, so prediction of landslide can be attributed to the prediction 
of surrounding rock stability. Many experts and scholars at home and abroad adopted different methods to conduct research studies and analysis on the rock mass stability, as shown in Table 1.

Each of the above methods has its advantages and disadvantages. Among them, Wang et al.'s method [27] directly assumes that sliding fracture plane is vertical in the absence of discussing different failure modes of landslide at mountain tunnel exit. It is generally known that its calculation mode is largely different from that of actual engineering situation. Meanwhile, there exists a relatively big discrepancy between the predicted and true position according to Wang et al.'s method [27]. Therefore, this method is worth further improvement and research.

In response to the above two limitations of Wang et al.'s method [27], this article firstly determines the most likely failure mode at mountain tunnel exit and establishes an optimal calculation mode based on the combination of theoretical analysis and actual engineering situation. Secondly, this article re-derives instability criterion based on the stress-transferring theory and examines the critical factor that influence solutions. Finally, the proposed method is applied to two case histories for verification.

\section{Failure Modes of Shallow-Buried Tunnel}

When the driving face of the mountain tunnel runs to the exit, the tunnel is close to the ground plane and rock mass is mostly loose deposits. The engineering practice shows that tunnel excavation will cause landslide because of relatively more shallow buried depth and poorer rock mass stability. F. Yang and J. S. Yang [28] used two methods, namely, a proposed rigid blocks failure mechanism and linear program, to solve upper bound solution of shallow-buried tunnel stability. Yang and Huang [29] used a new curved failure mechanism to derive landslide shape of shallow circular tunnel within the framework of upper bound theorem. Wang et al. [30] studied influencing factors of thickness-span ratio for shallow-buried tunnel. Liu et al. [31] studied failure modes of shallow-buried tunnel in weak rock under different thickness-span ratios through model test and numerical simulation. At the same time, Liu et al. [31] also drew the following conclusions. When the value of thickness-span ratio $x$ is smaller, it will form the penetrating landslide. When the value of thickness-span ratio $x$ is 3 , landslide cannot run to the plane and finally forms a shallow-buried pressure arch. When the value of thicknessspan ratio $x$ is 2.5 , the volume of landslide body and the extent of fractured regions will reach the biggest. Zhang et al. [32] studied failure process of landslide and the evolution laws of fracture plane for shallow-buried tunnel through model tests. At the same time, their research obtained that fracture plane was a curved plane and the angle between fracture plane and horizontal plane decreased correspondingly with the increase of rock mass damage range. In addition, some researchers concluded three failure modes of shallow-buried tunnel [33-38]: vertical subsidence (type I), forming a pressure arch (type II) and subsidence driven the soil of both (type III), as shown in Figure 1. In the figure, $h$,
TABLE 1: Summary of prediction method.

\begin{tabular}{|c|c|c|}
\hline \multirow{2}{*}{$\begin{array}{l}\text { Prediction } \\
\text { method }\end{array}$} & \multicolumn{2}{|r|}{ The existing research } \\
\hline & Researcher & Research means and results \\
\hline \multirow{2}{*}{$\begin{array}{l}\text { Field } \\
\text { monitoring } \\
\text { measurement }\end{array}$} & Lu et al. [14] & $\begin{array}{l}\text { Put forward the standard value } \\
\text { of landslide warning index }\end{array}$ \\
\hline & $\begin{array}{l}\text { Osman et al. } \\
{[15]}\end{array}$ & $\begin{array}{l}\text { Put forward a criterion of } \\
\text { landslide identification }\end{array}$ \\
\hline \multirow{4}{*}{$\begin{array}{l}\text { Various } \\
\text { nonlinear } \\
\text { theories } \\
\text { and } \\
\text { algorithms }\end{array}$} & $\mathrm{Xu}[16]$ & A gray cusp catastrophe model \\
\hline & $\begin{array}{l}\text { Hao et al. [17] } \\
\text { Cui et al. [18] }\end{array}$ & The Verhulst function model \\
\hline & $\begin{array}{c}\text { Chen et al. } \\
\text { [19] }\end{array}$ & $\begin{array}{l}\text { Nonlinear time series model } \\
\text { based on } \varepsilon \text {-SVR (support vector } \\
\text { regression) algorithm }\end{array}$ \\
\hline & Jiang [20] & $\begin{array}{l}\text { Nonlinear time series model } \\
\text { based on PSO-SVR algorithm }\end{array}$ \\
\hline \multirow{6}{*}{$\begin{array}{l}\text { Numerical } \\
\text { analysis }\end{array}$} & Kim [21] & \\
\hline & Faria $[22]$ & \\
\hline & $\begin{array}{l}\text { Xiang et al. } \\
\text { [23] }\end{array}$ & Finite element \\
\hline & $\begin{array}{c}\text { Alija et al. } \\
\text { [24] }\end{array}$ & \\
\hline & Zhang [25] & Boundary element \\
\hline & Liu et al. [26] & Discrete element \\
\hline $\begin{array}{l}\text { Geometric } \\
\text { method }\end{array}$ & $\begin{array}{c}\text { Wang et al. } \\
\text { [27] }\end{array}$ & $\begin{array}{l}\text { Obtained the instability criterion } \\
\text { of loose rock at tunnel exit based } \\
\text { on a simplified mechanics model }\end{array}$ \\
\hline
\end{tabular}

$h_{\mathrm{p}}, B$, and $\beta$, respectively, represent buried depth of tunnel, height of pressure arch, excavation width of tunnel, and rupture angle.

According to above research studies, we can see that landslide type of shallow-buried tunnel is roughly divided into penetrating type and forming a pressure arch type in the light of thickness-span ratio [39-41]. For type I, the buried depth is less than excavation width or 2-3 m, Wang et al. [27] obtained instability criterion of loose rock mass at mountain tunnel exit based on it. For type II, the buried depth is bigger than twice the height of a pressure arch; this generally does not occur at mountain tunnel exit. For type III, it often occurs at mountain tunnel exit and is the most common failure mode of shallow-buried tunnel. Therefore, this article studies prediction of landslide position when type III occurs at mountain tunnel exit.

\section{Instability Criterion and Prediction of Landslide Position}

3.1. The Generalized Model. When the driving face of the mountain tunnel runs to the exit, the tunnel often passes through thicker loose layer. Also, landslide is most likely to happen when driving face runs to a certain distance of loose layer [42-46]. In order to effectively predict landslide position of loose rock mass and considering the complexity of topographic and geological conditions at mountain tunnel exit, the topographic and geological conditions of the slope at mountain tunnel exit are simplified to mechanical model as shown in Figure 2. The upper part of the model is a loose 


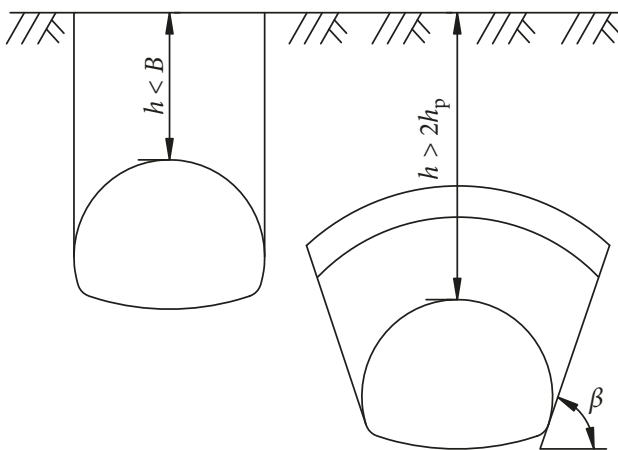

(a) I

(b) II

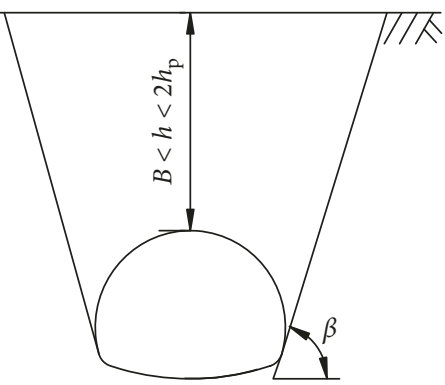

(c) III

Note:

$h=$ buried depth of tunnel

$H_{\mathrm{p}}=$ height of pressure arch

$B=$ excavation width of tunnel
$\beta=$ rupture angle

FIgURE 1: Three failure modes of shallow-buried tunnel.

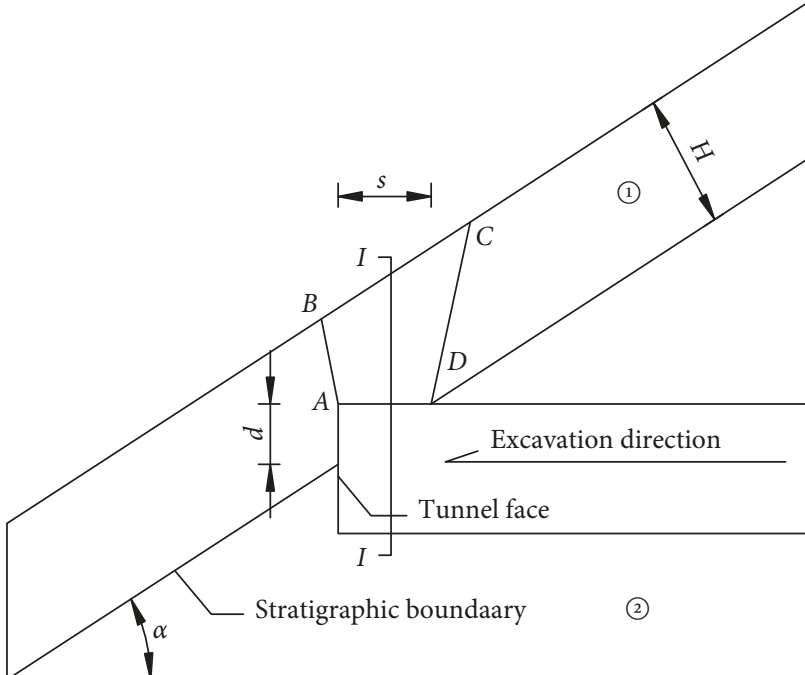

Note:

$\alpha=$ slope angle

$H=$ thickness of loose layer

$d=$ height of driving face running to loose layer

$s=$ horizontal distance of driving face running to loose layer

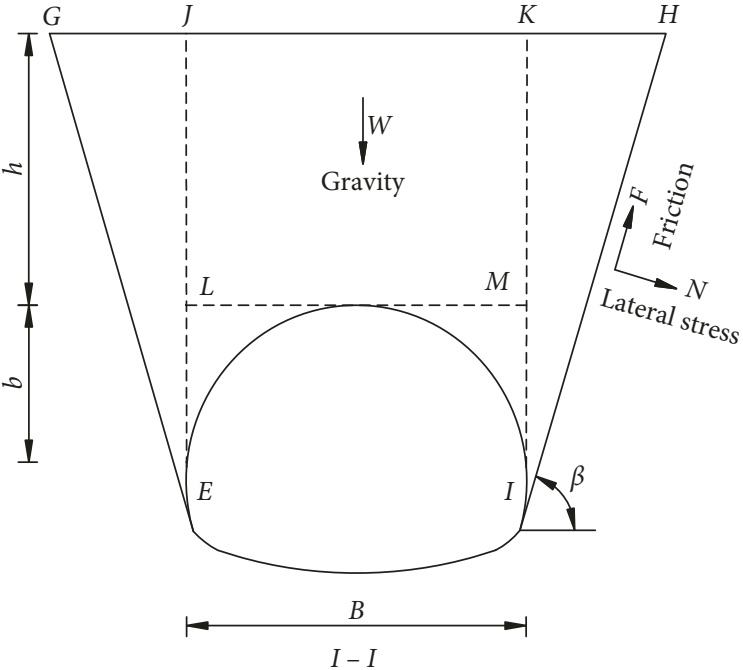

Note:

$\beta=$ rupture angel

$h=$ buried depth of tunnel

$b=$ height of tunnel excavation

$B=$ width of tunnel excavation

Figure 2: The simplified mechanical model.

and broken layer and the lower part is a relatively complete bedrock layer. In Figure $2, s, H, \alpha, d, h, b, B, \beta, W, F$, and $N$, respectively, represent horizontal distance of driving face running to loose layer, thickness of loose layer, slope angle, height of driving face running to loose layer, buried depth of tunnel, height of tunnel excavation, width of tunnel excavation, rupture angle, gravity, friction, and lateral stress.

3.2. Basic Assumptions. Considering the complexity of the exit, it is impossible to consider topographic and geological conditions completely. In order to study further, when instability criterion of loose rock mass at mountain tunnel exit is deduced based on the mechanical model above, make the following assumptions:
(1) Suppose that the slope of mountain tunnel exit is composed of two rock and soil layers, the upper part is a loose and broken layer and the lower part is a relatively complete bedrock layer.

(2) The failure of rock mass at mountain tunnel exit follows the Mohr-Coulomb yielding criterion.

(3) Suppose that sliding fracture plane formed in the rock mass is the oblique plane and there is rupture angle $\beta$ between the oblique plane and horizontal plane.

(4) Suppose that the initial stress field only considers the gravity stress of rock mass apart from the geological tectonic stress.

(5) The stress of rock mass is calculated as a plane-strain problem without considering the spatial effect. 


\subsection{Derivation of Instability Criterion}

3.3.1. Calculation of the Rupture Angle $\beta$. Take per meter along tunnel longitudinal direction to make analysis of the stress, as shown in Figure 2. According to the balance of the model in vertical direction, we can obtain the following equations:

$$
\begin{aligned}
& W-2 F \sin \theta-2 N \cos \theta=0, \\
& W=\gamma B h+\gamma(b+h)^{2} \cot \theta, \\
& F=N \tan \theta, \\
& A=\frac{b+h}{\cos \theta} .
\end{aligned}
$$

Substituting equations (2) and (3) into equation (1), we can obtain

$$
F=\frac{\gamma B h+\gamma(b+h)^{2} \cot \theta}{2(\sin \theta+\cos \theta \cot \theta)}
$$

Then, the shear stress on the fracture plane $H I$ is

$$
\tau=\frac{F}{A} \text {. }
$$

Substituting equations (4) and (5) into equation (6), we can obtain

$$
\tau=\frac{\gamma B h+\gamma(b+h)^{2} \cot \theta}{2(b+h)(\tan \theta+\cot \theta)} .
$$

According to the Mohr-Coulomb failure criterion, the maximum shear stress $\tau_{\max }$ on the fracture plane $H I$ is

$$
\tau_{\max }=\sigma_{\mathrm{n}} \tan \varphi+c
$$

where $\sigma_{n}=$ normal stress of the fracture plane; $\varphi=$ internal friction angle; and $c=$ cohesion of rock mass. Also, $\sigma_{n}$ is

$$
\sigma_{n}=\frac{N}{A}=\frac{\gamma B h+\gamma(b+h)^{2} \cot \theta}{2(b+h)\left(1+\tan ^{2} \theta\right)} \text {. }
$$
$H I$ is

So, the function of safety degree on the fracture plane

$$
f=\tau_{\max }-\tau,
$$

when the first derivative of the $f$ versus $\theta$ theta is 0 , which is $(d f / d \theta)=0$, the most dangerous rupture angle is obtained as follows:

$$
\begin{aligned}
\tan \phi= & \frac{\tan \beta+\cot \beta-\left(\left(x /(x+\eta)^{2}\right)+\cot \beta\right)\left(1-\tan ^{2} \beta\right)}{1+2\left(\left(x /(x+\eta)^{2}\right)+\cot \beta\right) \tan ^{2} \beta \sin \beta} \\
& \cdot \sin ^{2} \beta,
\end{aligned}
$$

where $x=$ the ratio of thickness-span $(x=h / B)$ and $\eta=$ the ratio of rise-span $(\eta=b / B)$.

So far, it is known that rupture angle $\beta$ can be defined uniquely by $x, \eta$, and $\varphi$.
3.3.2. Instability Criterion. When the driving face runs to the position as shown in Figure 2, force analysis of the thin-layer element with $d z$ thick was conducted, as shown in Figure 3. Both sides of thin-layer element is subjected to friction $d F$ and lateral stress $d N$. With sliding of the thin-layer element with gravity, friction will transfer effect of the sliding to the rock mass on both sides, resulting in stress transferring. When driving to the upper layer of loose rock mass in a certain distance, landslide occurs and the shape of landslide body is similar to a funnel. So far, we know that landslide is related to not only the parameters determined by Wang et al. [27] but also the parameter $\beta$ which is used for controlling landslide scope. Therefore, the discriminant function of landslide is

$$
Y=y(s, H, \alpha, \gamma, c, \varphi, \beta, T) \text {, }
$$

where $s, H, \alpha, \gamma, c, \varphi, \beta$, and $T$ are horizontal distance of driving face running to loose layer, thickness of loose layer, slope angle, unit weight of loose soil, cohesion of loose soil, friction angle of loose soil, rupture angle, and initial support force, respectively.

According to the Mohr-Coulomb law, the vertical components of friction force and lateral stress on the sliding plane of the thin-layer element are, respectively,

$$
\begin{aligned}
d F_{\mathrm{V}} & =\left(\sigma_{\mathrm{n}} \tan \varphi+c\right) \cos \beta d z, \\
d N_{\mathrm{V}} & =\sigma_{\mathrm{n}} \cot \beta d z,
\end{aligned}
$$

where $\sigma_{\mathrm{n}}=$ normal stress on oblique section.

Suppose horizontal coefficient of lateral stress is $\zeta$, then vertical and horizontal principal stress $\left(\sigma_{\mathrm{V}}, \sigma_{\mathrm{H}}\right)$ and the corresponding shear stress $\tau$ are, respectively,

$$
\begin{aligned}
\sigma_{\mathrm{V}} & =\gamma z, \\
\sigma_{\mathrm{H}} & =\zeta \sigma_{\mathrm{V}}, \\
\tau & =\sigma_{\mathrm{H}} \tan \varphi+c,
\end{aligned}
$$

where $z$ represents the vertical distance from rupture point to plane.

According to the basic theory about plane problem in elastic mechanics, that is, stress calculation at a point in an oblique section, we can obtain

$$
\sigma_{\mathrm{n}}=\sigma_{\mathrm{H}} \sin ^{2} \beta-\sigma_{\mathrm{V}} \cos ^{2} \beta+\tau \sin 2 \beta .
$$

Based on geometrical relation of the triangle theory, height $(d)$ of driving face running to loose layer and vertical projection lengths $\left(z_{1}\right.$ and $\left.z_{2}\right)$ of the sliding planes ( $A B$ and $C D)$ are, respectively,

$$
\begin{gathered}
d=s \tan \alpha \\
z_{1}=\frac{H}{\cos \alpha}-d, \\
z_{2}=\frac{H \sin \beta}{\sin (\beta-\alpha)} .
\end{gathered}
$$

So, the discriminant function of landslide is 


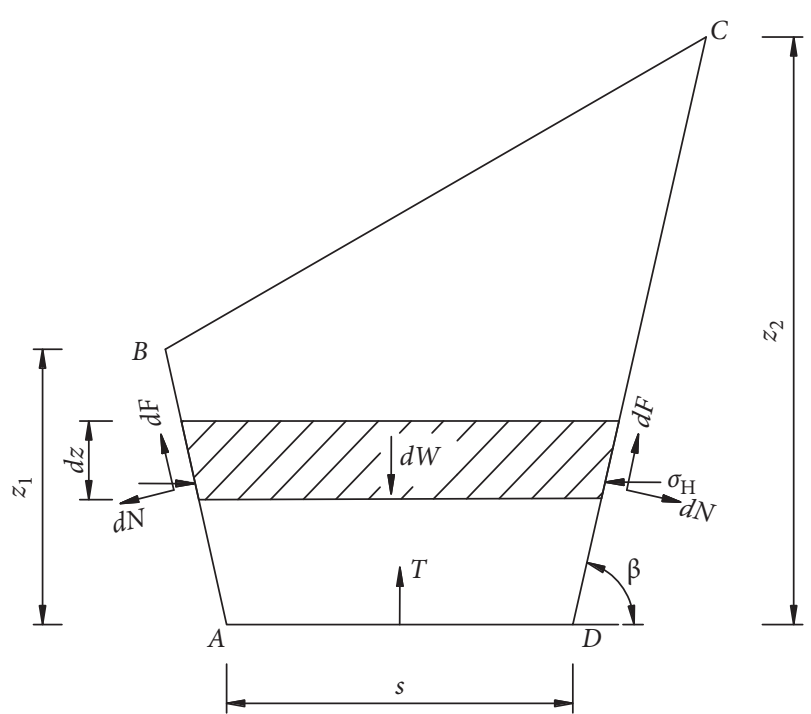

Figure 3: Stress analysis of thin-layer element.

$$
\begin{aligned}
Y= & \int_{0}^{z_{1}}\left(d F_{\mathrm{V}}+d N_{\mathrm{V}}\right)+\int_{0}^{z_{2}}\left(d F_{\mathrm{V}}+d N_{\mathrm{V}}\right) \\
& +T-\left(\int_{0}^{z_{1}} \gamma\left(s+\frac{z}{\tan \beta}\right) d z+\frac{1}{2} \int_{z_{1}}^{z_{2}} \gamma\left(s+\frac{3 z_{1}-z_{2}}{\tan \beta}\right) d z\right) .
\end{aligned}
$$

Substituting equations (17) and (18) into equation (19), we can obtain

$$
Y=p s^{2}+q s+r
$$

where $p, q$, and $r$, respectively, are

$$
\begin{aligned}
p= & \frac{1}{2} \gamma \tan \alpha\left(\begin{array}{c}
\xi \tan \varphi \tan \alpha \sin ^{2} \beta+\xi \tan \varphi^{2} \tan \alpha \sin 2 \beta \\
-\tan \varphi \tan \alpha \cos ^{2} \beta-\tan \alpha \cot \beta-1
\end{array}\right), \\
q= & \gamma \tan \varphi \frac{H \tan \alpha}{\cos \alpha}\left(\xi \sin ^{2} \beta+\xi \sin 2 \beta-\cos ^{2} \beta\right) \\
& +\gamma \frac{H \sin \beta}{\sin (\beta-\alpha)}+\gamma \frac{H \tan \alpha}{\tan \beta \cos \alpha}-\frac{H \tan \alpha \sin \beta}{\tan \beta \sin (\beta-\alpha)} \\
& +c \tan \alpha(\tan \varphi \sin 2 \beta+1), \\
r= & \xi \gamma \tan \varphi\left(\sin ^{2} \beta\left(\frac{H}{\cos \alpha}\right)^{2}-\tan \varphi \sin 2 \beta\left(\frac{H \sin \beta}{\sin (\beta-\alpha)}\right)^{2}\right) \\
& +\gamma\left(\frac{H}{\cos \alpha}\right)^{2}\left(\frac{1}{2} \cot \beta-\tan \varphi \cos ^{2} \beta\right) \\
& +2 c\left(\frac{H}{\cos \alpha}+\tan \varphi \sin 2 \beta\left(\frac{H \sin \beta}{\sin (\beta-\alpha)}\right)^{2}\right)+T .
\end{aligned}
$$

Setting $Y=0$, we can obtain

$$
p s^{2}+q s+r=0 .
$$

The discriminant of equation (22) is

$$
\Delta=q^{2}-4 p r
$$

According to the values of $\Delta$, at $\Delta=0, Y \geq 0$ and rock mass is in the limit state at $Y=0$. At $\Delta>0, Y$ can be less than zero and landslide may occur. Then, the two solutions of equation (22) are, respectively,

$$
\begin{aligned}
& s_{1}=\frac{-q-\sqrt{q^{2}-4 p r}}{2 p}, \\
& s_{2}=\frac{-q+\sqrt{q^{2}-4 p r}}{2 p} .
\end{aligned}
$$

According to the above judgment, landslide occurs at $Y<0$. At this time, $s$ needs to satisfy the following equation:

$$
s_{1}<s<s_{2} \text {. }
$$

In addition, we can see from Figure 2 that $s$ also needs to satisfy the following equation:

$$
0 \leq s \leq \frac{H}{\sin \alpha} \text {. }
$$

So far, it is known that equation (23) can be used for judging the possibility of landslide at mountain tunnel exit. Equations (26) and (27) can accurately determine landslide position of loose rock mass at mountain tunnel exit.

\section{Applied to Case Histories}

In order to verify the correctness and superiority of the proposed method in this article, the instability criterion derived is applied to two projects to analyze and predict landslide position of loose rock mass at the tunnel exit.

\subsection{Case 1}

4.1.1. General Situation of Project. A tunnel is located in Jining-Hohhot section of the Beijing-Hohhot expressway, and the tunnel zone belongs to denuded hills and mountain landform with big topographic relief, dry and windy climate, less rainfall which mainly concentrates in June, July, and August, and larger evaporation. At the same time, plane water in the tunnel zone is undeveloped and ground water is mainly a small amount of weathering fissure water in bedrock. The natural slope of mountain is $10^{\circ}$ to $40^{\circ}$, and vegetation is undeveloped. According to the geological exploration results and ground survey, the upper layer is silt, sand, and gravel of Quaternary Pleistocene series $\left(\mathrm{Q}_{4}^{\mathrm{dl}}\right)$ and the lower layer is granite of Jining Group, Upper Paleozoic (Ar).

The tunnel was designed using the construction form of one-way driving. The right tunnel exit of Jining section is located in the slope about $30^{\circ}$. The upper layer covered by approximately $12 \mathrm{~m}$ Quaternary silt, gravel, and strongly weathered granite, and the lower layer is mainly moderately weathered and more complete granite. Tunnel landslides occur when it is excavated to $\mathrm{K} 196+200$. The slope geography, the distribution of rock and soil, and landslide position are shown in Figure 4. 


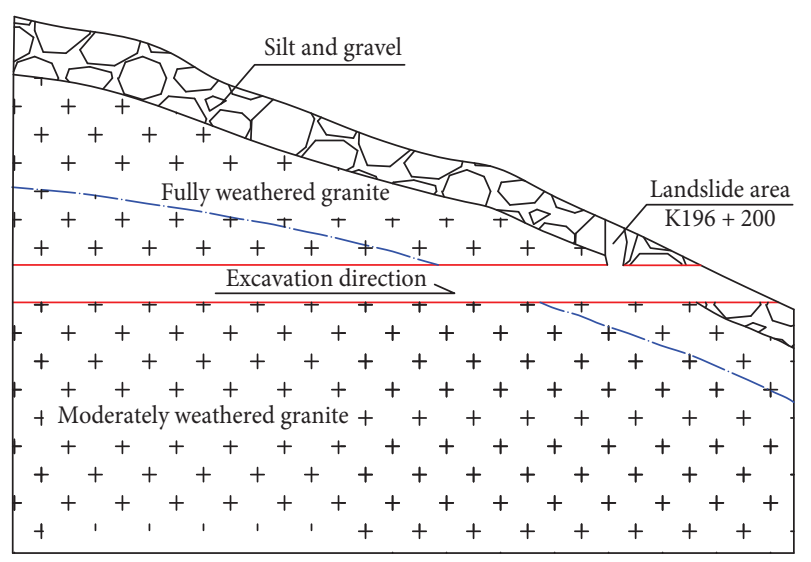

8 Silt and gravel

++++7 Granite

Boundary of weathered zones

FIgURE 4: Slope geography and rock soil distribution.

4.1.2. Prediction of Landslide Position. According to the report of engineering geological exploration and site survey, the relevant calculation parameters are shown in Table 2.

Take the parameters in Table 1 into equation (22) and obtain the coefficients ( $p, q$, and $r$ ), respectively:

$$
\left\{\begin{array}{l}
p=6135.37 \\
q=-318037.51 \\
r=1296227.01
\end{array}\right.
$$

Take $p, q$, and $r$ into equation (23) and obtain " $\Delta=6.9 \times 10^{10}>0$," so landslide can occur.

Take $p, q$, and $r$ into equations (24) and (25) and obtain " $s_{1}=4.5, s_{2}=47.4$." At the same time, take $H$ and $\alpha$ into equation (27) and obtain " $0 \leq s \leq 24$." Finally obtain “4.5<s $\leq 24$."

So far, it is known that landslide occurs when the distance of driving face running to loose layer is longer than $4.5 \mathrm{~m}$. Also, the corresponding landslide position is K196 + 199.8 which agrees well with the actual landslide position $(\mathrm{K} 196+200)$ with only $0.10 \%$ out. However, the corresponding landslide position is K196 +198.7 based on the method of Wang et al. [27] and the error is $0.65 \%$ compared with the actual landslide position.

The comparisons between the obtained results of this article's method and Wang et al.'s method [27] show that the error is reduced by $0.55 \%$.

\subsection{Case 2}

4.2.1. General Situation of Project. Ma'anshan Tunnel is located in Jinhua section of the Zhu Yong Expressway. The tunnel zone, of a hilly area with middle-low mountains and narrow valleys, is characterized by high in the middle and low on the east and west ends, narrow and curved streams, quite developed branched water system, and well developed vegetation. The top of the hill is $367.08 \mathrm{~m}$ above sea level, and
TABLE 2: Relevant calculation parameters.

\begin{tabular}{lc}
\hline Parameters & Values \\
\hline Slope angle, $\alpha\left(^{\circ}\right)$ & $30^{\circ}$ \\
Thickness of loose layer, $H(\mathrm{~m})$ & 12 \\
Cohesion, $c(\mathrm{kPa})$ & 10 \\
Internal friction angle, $\varphi\left(^{\circ}\right)$ & $25^{\circ}$ \\
Unit weight, $\gamma\left(\mathrm{kN}, \mathrm{m}^{3}\right)$ & 21 \\
Lateral pressure coefficient, $\zeta$ & 0.4 \\
Initial support force, $T(\mathrm{kPa})$ & 0 \\
Thickness-span ratio, $x$ & 1.2 \\
Rise-span ratio, $\eta$ & 0.8 \\
\hline
\end{tabular}

the natural slope of the terrain is $30^{\circ}$ to $35^{\circ}$. During the rainy season, streams are swift with rising and falling speedily, but they have smaller volume of flow and are partly dry in the dry season.

Ma'anshan tunnel was designed as one way with two lanes. The tunnel exit is located at the slope which is covered with approximately 10 meters thick Quaternary loose deposits and completely weathered tuff. Weathering fracture is extremely growing fast and rock mass structure is loose. The lower layer is weakly weathered tuff and the rock mass is relatively complete. The right tunnel of Ma'anshan Tunnel was constructed by two-step method from the entrance to the exit. The landslide occurred in $\mathrm{K} 97+582 \sim \mathrm{K} 97+585$ section at 18:00 hours in April 19, 2016. The earth's plane appeared the subsidence area of a funnel with $6 \mathrm{~m}$ in diameter. The slope geography, the distribution of rock and soil, and landslide position are shown in Figure 5.

4.2.2. Prediction of Landslide Position. According to the report of engineering geological exploration and site survey, the relevant calculation parameters are shown in Table 3.

Take the parameters in Table 2 into equation (22) and obtain the coefficients ( $p, q$, and $r$ ), respectively:

$$
\left\{\begin{array}{l}
p=5801.45 \\
q=-256837.38 \\
r=1059050.82
\end{array}\right.
$$

Take $p, q$, and $r$ into equation (23) and obtain " $\Delta=4.14 \times 10^{10}>0$," so landslide can occur.

Take $p, q$, and $r$ into equations (24) and (25) and obtain " $s_{1}=4.6, s_{2}=39.7$." At the same time, take $H$ and $\alpha$ into equation (27) and obtain " $0 \leq s \leq 20$." Finally, obtain "4.6<s $\leq 20$."

So far, it is known that landslide occurs when the distance of driving face running to loose layer is longer than 4.6 meters and the corresponding landslide position is K97 +584.6 which agrees well with the actual landslide position $(\mathrm{K} 97+585)$ with only $0.07 \%$ out. However, the corresponding landslide position is $\mathrm{K} 97+584.05$ based on the method of Wang et al. [27] and the error is $0.16 \%$ compared with the actual landslide position.

The comparisons between the obtained results of this article's method and Wang et al.'s method [27] show that the error is reduced by $0.09 \%$. 


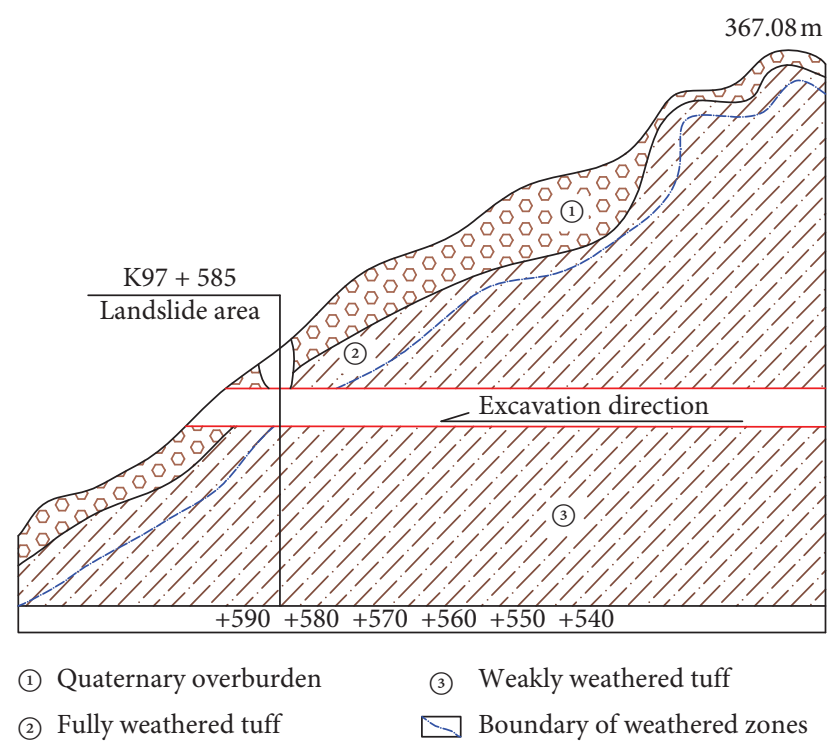

FIGURE 5: Slope geography and rock soil distribution.

TABLE 3: Relevant calculation parameters.

\begin{tabular}{lc}
\hline Parameters & Values \\
\hline Slope angle, $\alpha\left(^{\circ}\right)$ & $30^{\circ}$ \\
Thickness of loose layer, $H(\mathrm{~m})$ & 10 \\
Cohesion, $c(\mathrm{kPa})$ & 20 \\
Internal friction angle, $\varphi\left(^{\circ}\right)$ & $26^{\circ}$ \\
Unit weight, $\gamma\left(\mathrm{kN}, \mathrm{m}^{3}\right)$ & 19 \\
Lateral pressure coefficient, $\zeta$ & 0.38 \\
Initial support force, $T(\mathrm{kPa})$ & 0 \\
Thickness-span ratio, $x$ & 0.8 \\
Rise-span ratio, $\eta$ & 0.7 \\
\hline
\end{tabular}

\subsection{Result Analysis}

(1) By the method of this article, the errors between predicted and actual position are only $0.10 \%$ and $0.07 \%$, respectively. However, according to the method derived by Wang et al. [27], the errors are $0.65 \%$ and $0.16 \%$, respectively. Also, compared with Wang et al.'s method [27], the errors are reduced by $0.55 \%$ and $0.09 \%$, respectively. In addition, it suggests that it is feasible, reliable, and in better agreement with the actual situation to use this article's method for prediction of landslide position at mountain tunnel exit.

(2) Although the comparisons between the obtained results and the methods by Wang et al. [27] showed a very little difference, we can see that the thicknessspan ratio $x$ and rise-span ratio $\eta$ influenced the obtained solutions at roughly the same parameters $s$, $H, \alpha, \gamma, c, \varphi$, and $T$ from two case histories. In other words, rupture angle $\beta$ influences the obtained solutions according to equation (11). In addition, it indicated that basic parameters of rock mass are the most important factors controlling the obtained solutions.

\section{Conclusion}

In response to limitations of Wang et al.'s method, we combined theoretical analysis and actual engineering situation to explore an optimal calculation mode; besides, we rededuced instability criteria and discriminant for landslide position based on the stress-transferring theory and examined the factors that influence solutions. The main contributions of this article are as follows:

(1) Once landslide occurs at mountain tunnel exit, it may run to the ground and usually form the penetrating landslide. Type III, as shown in Figure 1, is the most common failure mode of shallow-buried tunnel and often occurs at mountain tunnel exit.

(2) Landslide of shallow-buried tunnel is related to not only the parameters determined by Wang et al. but also rupture angle $\beta$. Role of rupture angle $\beta$ is to control landslide scope. In addition, rupture angle $\beta$ can be defined uniquely by thickness-span ratio $x$, rise-span ratio $\eta$, and internal friction angle $\varphi$.

(3) Based on stress-transferring theory, we obtained instability criteria and discriminant for landslide position. Equation (23) can be used for judging the possibility of landslide at mountain tunnel exit. Equations (26) and (27) can accurately determine landslide position of loose rock mass at mountain tunnel exit.

(4) The improved method is applied to two case histories, and the errors between predicted and actual position are only $0.10 \%$ and $0.07 \%$, respectively. Also, compared with Wang et al.'s method, the errors are reduced by $0.55 \%$ and $0.09 \%$, respectively. It suggests that it is feasible, reliable, and in better agreement with the actual situation to use this article's method for prediction of landslide position at mountain tunnel exit.

\section{Data Availability}

The data used to support the findings of this study are included within the article.

\section{Conflicts of Interest}

The authors declare that there are no conflicts of interest regarding the publication of this article.

\section{Acknowledgments}

This research was funded by the National Key R\&D Program of China (grant no. 2017YFC0805306), the National Nature Science Foundation of China (NSFC) (grant no. 41702287), and the Fundamental Research Funds for the Central Universities (grant no. 300102218517). These financial supports are gratefully acknowledged.

\section{References}

[1] F. Gan, "Construction technology of tunnel one-way driving," China Municipal Technology, vol. 30, no. 1, pp. 118-119, 2012. 
[2] Y. Wei, X. Gao, F. Wang, and Y. Zhong, "Nonlinear strain distribution in a field-instrumented concrete pavement slab in response to environmental effects," Road Materials and Pavement Design, vol. 20, no. 2, pp. 367-380, 2019.

[3] Y. Wei, X. Gao, and S. Liang, "A combined SPM/NI/EDS method to quantify properties of inner and outer C-S-H in OPC and slag-blended cement pastes," Cement and Concrete Composites, vol. 85, pp. 56-66, 2018.

[4] J. X. Lai, K. Y. Wang, J. L. Qiu, F. Y. Niu, J. B. Wang, and J. X. Chen, "Vibration response characteristics of the cross tunnel structure," Shock and Vibration, vol. 2016, Article ID 9524206, 16 pages, 2016.

[5] R. Ren, H. Zhou, Z. Hu, S. He, and X. Wang, "Statistical analysis of fire accidents in Chinese highway tunnels 20002016," Tunnelling and Underground Space Technology, vol. 83, pp. 452-460, 2019.

[6] Z.-F. Wang, W.-C. Cheng, and Y.-Q. Wang, "Investigation into geohazards during urbanization process of Xi'an, China," Natural Hazards, vol. 92, no. 3, pp. 1937-1953, 2018.

[7] J. L. Qiu, H. Q. Liu, J. X. Lai, H. P. Lai, J. X. Chen, and $\mathrm{K}$. Wang, "Investigating the long-term settlement of a tunnel built over improved loessial foundation soil using jet grouting technique," Journal of Performance of Constructed Facilities, vol. 32, no. 5, article 04018066, 2018.

[8] Y. Q. Wang, Z. F. Wang, and W. C. Cheng, "A review on land subsidence caused by groundwater withdrawal in Xi'an, China," Bulletin of Engineering Geology and the Environment, 2018.

[9] J. L. Qiu, Y. W. Qin, J. X. Lai et al., "Structural response of the metro tunnel under local dynamic water environment in loess strata," Geofluids, vol. 2019, Article ID 8541959, 16 pages, 2019.

[10] Y. Q. Wang, W. K. Kong, and Z. F. Wang, "Effect of expanding a rectangular tunnel on adjacent structures," Advances in Civil Engineering, vol. 2018, Article ID 1729041, 13 pages, 2018.

[11] H. Z. Yu, "Monitoring technique of tunnel landslide in tunnel construction," Chinese Journal of Highway, vol. 9, no. 9, pp. 157-160, 2002.

[12] S. Li, S. Li, Q. Zhang et al., "Predicting geological hazards during tunnel construction," Journal of Rock Mechanics and Geotechnical Engineering, vol. 2, no. 3, pp. 232-242, 2010.

[13] P. F. Li and Y. Zhao, "Performance of a multi-face tunnel excavated in loess ground based on field monitoring and numerical modeling," Arabian Journal of Geosciences, vol. 9, no. 14, p. 640, 2016.

[14] W. Lu, R. Zhu, and X. Chi, "Forecasting and criterion of rock slid during excavation in shale," Rock and Soil Mechanics, vol. 14, no. 1, pp. 83-90, 1993.

[15] A. S. Osman, R. J. Mair, and M. D. Bolton, "On the kinematics of 2D tunnel collapse in undrained clay," Géotechnique, vol. 56, no. 9, pp. 585-595, 2006.

[16] J. C. Xu, "Research on gray-cusp-catastrophic destabilization prediction model of tunnel surrounding rock and primary support system," Chinese Journal of Rock Mechanics \& Engineering, vol. 27, no. 6, pp. 1181-1187, 2008.

[17] Z. Hao, Q. Liu, and B. Liu, "Displacement prediction and stabilization forecast of surrounding rock of highway tunnel excavation," Highway, vol. 33, no. 8, pp. 197-202, 2004.

[18] L. Cui, S. Liu, Z. Li, and F. Precision, "A grey discrete verhulst model," Systems Engineering \& Electronics, vol. 33, no. 33, pp. 590-593, 2011.

[19] Q. N. Chen, Y. X. Zhang, M. H. Zhao et al., "Forecasting evolution of tunnel surrounding rock displacement by
E-SVR," Rock and Soil Mechanics, vol. 27, no. 4, pp. 591-593, 2006.

[20] A. Jiang, "Forecasting nonlinear time series of surrounding rock deformations of underground cavern based on PSOSVM," Rock and Soil Mechanics, vol. 28, no. 6, pp. 1176-1180, 2007.

[21] Y. M. Kim, "A study on tunnel stability with tunnel construction by finite element method," Journal of the Korean Society of Civil Engineers, vol. 22, no. 2C, pp. 173-180, 2002.

[22] P. O. Faria, "A simulation for landslide of tunnels using numerical limit analysis and conventional finite elements," in Proceedings of the Workshop de Tecnologia da Informação aplicada ao Meio Ambiente-CBComp 2004 Simulação e Modelagem, pp. 764-769, Itajaí, Brasil, 2004.

[23] A. T. Xiang, H. H. Zhu, W. Q. Ding, and M. H. Jia, "Mouth slope failure mechanism of shallow embedded and doublearch tunnel with partial-pressure," Chinese Journal of Underground Space and Engineering, vol. 4, no. 1, pp. 73-79, 2008.

[24] S. Alija, F. J. Torrijo, and M. Quinta-Ferreira, "Study of the unexpected collapse of the Ampurdán tunnel (Spain) using a finite elements model," Bulletin of Engineering Geology and the Environment, vol. 73, no. 2, pp. 451-463, 2014.

[25] Y. Z. Zhang, "An estimation of fuzzy reliability of distinct element method in prediction of plane subsidence due to coal mining," Journal of Coal Science \& Engineering China, vol. 4, no. 2, pp. 7-12, 1998.

[26] S. H. Liu, D. A. Sun, and Y. Wang, "Numerical study of soil collapse behavior by discrete element modelling," Computers and Geotechnics, vol. 30, no. 5, pp. 399-408, 2003.

[27] Y. C. Wang, Y. Q. Shang, X. H. Xu, Y. H. Xiao, and X. S. Yan, "Time and space prediction of landslide of loose wall rock at tunnel exit," Chinese Journal of Geotechnical Engineering, vol. 32, no. 12, pp. 1868-1874, 2010.

[28] F. Yang and J. S. Yang, "Stability of shallow tunnel using rigid blocks and finite-element upper bound solutions," International Journal of Geomechanics, vol. 10, no. 6, pp. 242-247, 2010.

[29] X. L. Yang and F. Huang, "Collapse mechanism of shallow tunnel based on nonlinear Hoek-Brown failure criterion," Tunnelling and Underground Space Technology, vol. 26, no. 6, pp. 686-691, 2011.

[30] X. Wang, S. Zhou, J. Chi, and X. Wu, "Study on shallowburied tunnel thickness-span ratio in upper-soft and lowerhard ground," Chinese Journal Underground Space and Engineering, vol. 7, no. 4, pp. 700-705, 2011.

[31] J. Liu, X. R. Liu, Y. Lai, Z. J. Wang, and Y. Z. Xiang, "Model test and numerical simulation study on failure mode of shallow tunnel," Electronic Journal of Geotechnical Engineering, vol. 19, no. 17, pp. 16815-16826, 2014.

[32] C. P. Zhang, K. H. Han, D. L. Zhang, H. Li, and Y. Cai, "Experimental study on landslide characteristics and evolution law of urban weak surrounding rock tunnel," China Journal of Rock Mechanics and Engineering, vol. 33, no. 12, pp. 2433-2442, 2014.

[33] C. González and C. Sagaseta, "Patterns of soil deformations around tunnels. Application to the extension of Madrid Metro," Computers \& Geotechnics, vol. 28, no. 6-7, pp. 445-468, 2001.

[34] H. Basahel and H. Mitri, "Application of rock mass classification systems to rock slope stability assessment: a case study," Journal of Rock Mechanics and Geotechnical Engineering, vol. 9, no. 6, pp. 993-1009, 2017.

[35] A. Verruijt, C. Sagaseta, and O. E. Strack, "Predictions of ground deformations in shallow tunnels in clay ${ }^{1}$. Wei-I. Chou, 
Antonio Bobet, tunnelling and underground space technology, vol. 17, pp 3-19," Tunnelling and Underground Space Technology, vol. 18, no. 1, pp. 93-94, 2003.

[36] Z.-F. Wang, S.-L. Shen, and G. Modoni, "Enhancing discharge of spoil to mitigate disturbance induced by horizontal jet grouting in clayey soil: theoretical model and application," Computers and Geotechnics, vol. 111, pp. 222-228, 2019.

[37] Y. Q. Wang, S. Xu, R. Ren, S. Zhang, and Z. Ren, "Application of the twin-tube complementary ventilation system in largeslopping road tunnels in China," International Journal of Ventilation, pp. 1-20, 2019.

[38] Z. F. Wang, J. S. Shen, and W. C. Cheng, "Simple method to predict ground displacements caused by installing horizontal jet-grouting columns," Mathematical Problems in Engineering, vol. 2018, Article ID 1897394, 11 pages, 2018.

[39] M. Fraldi and F. Guarracino, "Analytical solutions for collapse mechanisms in tunnels with arbitrary cross sections," International Journal of Solids and Structures, vol. 47, no. 2, pp. 216-223, 2010.

[40] S. Senent and R. Jimenez, "A tunnel face failure mechanism for layered ground, considering the possibility of partial landslide," Tunnelling and Underground Space Technology, vol. 47, pp. 182-192, 2014.

[41] P. Chambon and J. F. Corté, "Shallow tunnels in cohesionless soil: stability of tunnel face," Journal of Geotechnical Engineering, vol. 120, no. 7, pp. 1148-1165, 1994.

[42] R. Ren, S. Xu, Z. Ren et al., "Numerical investigation of particle concentration distribution characteristics in twintunnel complementary ventilation system," Mathematical Problems in Engineering, vol. 2018, Article ID 1329187, 13 pages, 2018.

[43] T. G. Jie and D. X. Bi, "The predictive model of the tunnel landslide height based on BP artificial neural network and multiple regression," Journal of Mountain Science, vol. 21, no. 4, pp. 507-513, 2003.

[44] X. Bian, Y. J. Cui, and X. Z. Li, "Voids effects on the swelling behaviour of compacted bentonite," Geotechnique, pp. 1-13, 2018.

[45] Y. Wei, J. Huang, and S. Liang, "Measurement and modeling concrete creep considering relative humidity effect," $\mathrm{Me}$ chanics of Time-Dependent Materials, 2019.

[46] W.-I. Chou and A. Bobet, "Predictions of ground deformations in shallow tunnels in clay," Tunnelling and Underground Space Technology, vol. 17, no. 1, pp. 3-19, 2002. 


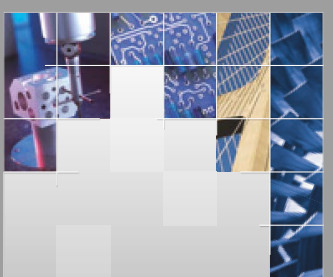

\section{Enfincering}
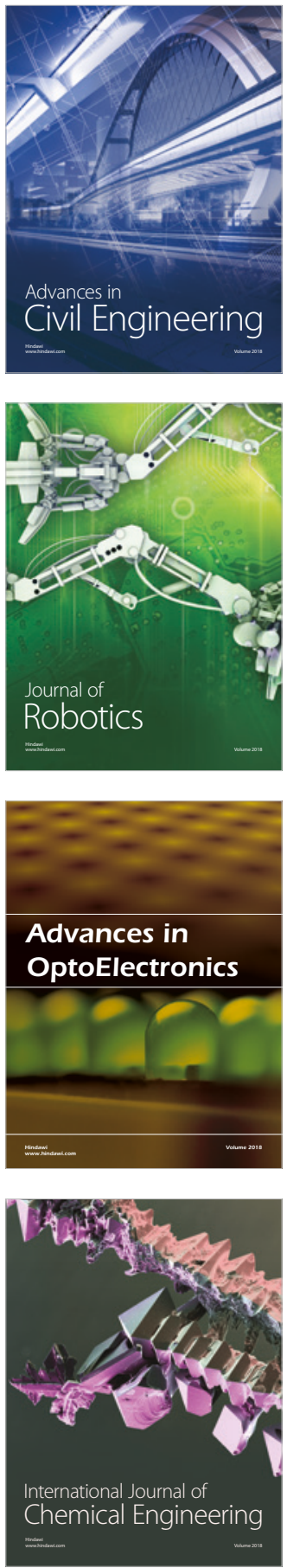

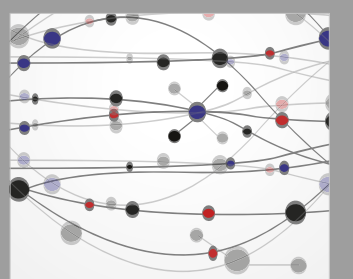

\section{Rotating \\ Machinery}

The Scientific World Journal

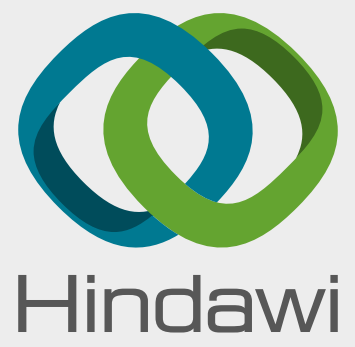

Submit your manuscripts at

www.hindawi.com
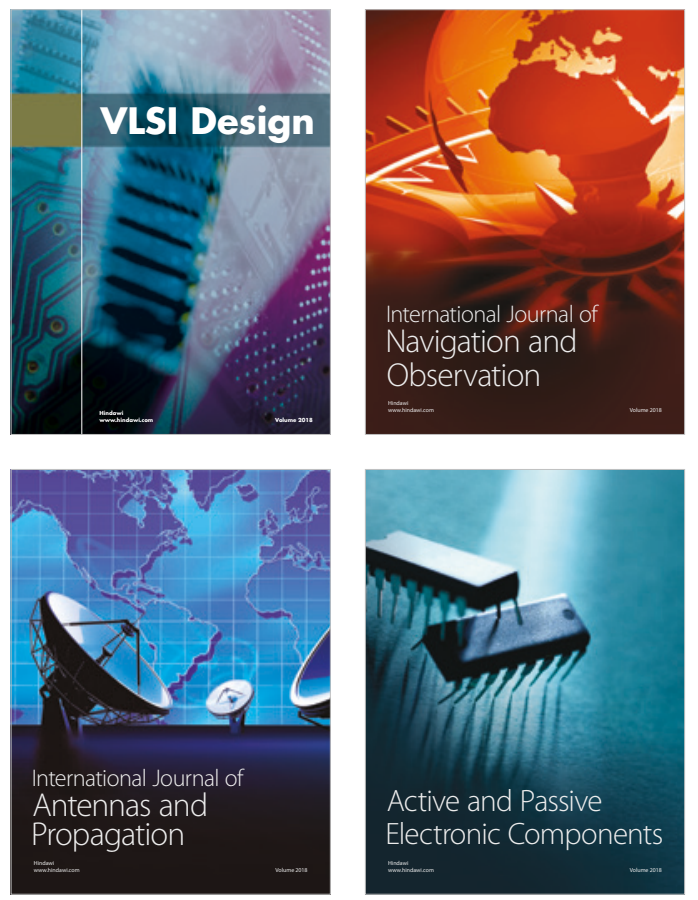
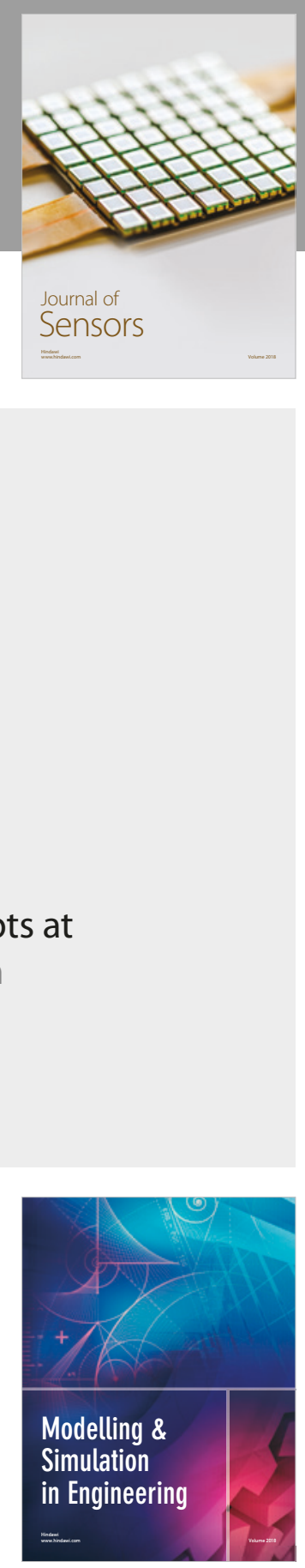

\section{Advances \\ Multimedia}
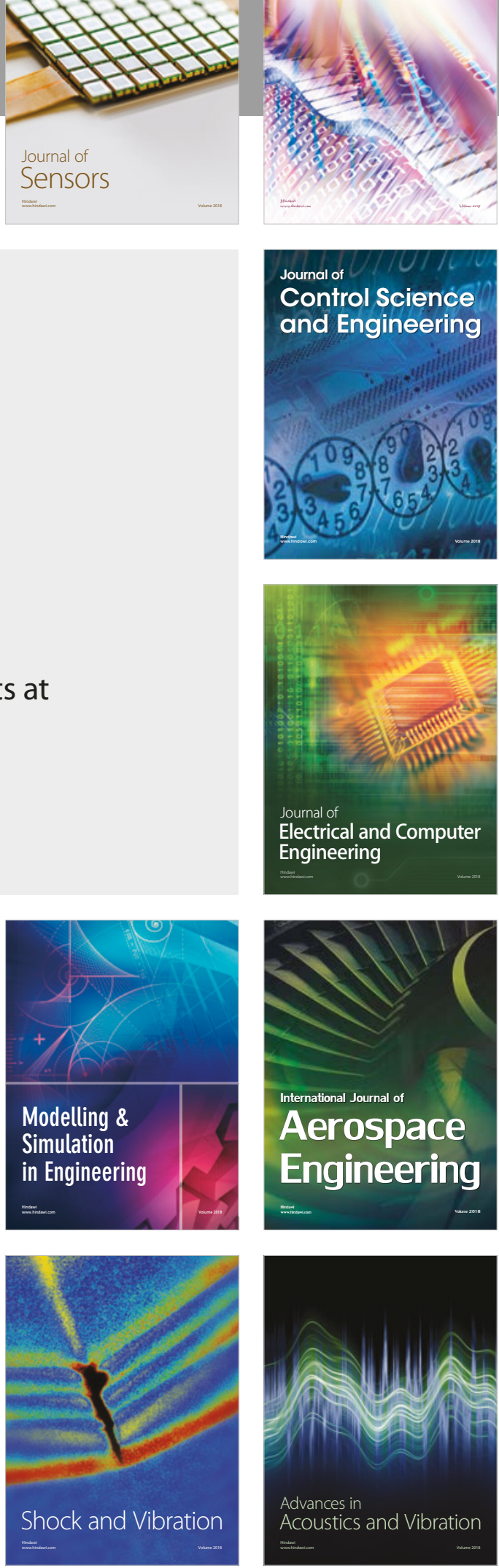